\title{
AETIOLOGICAL AGENTS OF EAR DISCHARGE: A TWO YEAR RE- VIEW IN A TEACHING HOSPITAL IN GHANA
}

\author{
L. APPIAH-KORANG ${ }^{1}$, S. ASARE-GYASI ${ }^{1}$ A. E. YAWSON ${ }^{2}$, K. SEARYOH ${ }^{3}$ \\ ${ }^{1}$ Department of Microbiology Korle-Bu Teaching Hospital, Accra, Ghana, ${ }^{2}$ Department of Community \\ Health, University of Ghana Medical School, College of Health Sciences, Accra, Ghana, ${ }^{3}$ ENT Department \\ Korle-Bu Teaching Hospital, Accra, Ghana
}

DOI: http://dx.doi.org/10.4314/gmj.v48i2.6

Corresponding author: Dr. Larbi Appiah-Korang

Email:appiahl@yahoo.com

Conflict of Interest: None declared

\section{SUMMARY}

Background: The discharging ear is a common presentation in medical practice affecting all age groups but primarily children. This study shows the current aetiological causes of ear discharge and their antibiograms, data which would guide empirical treatment of ear infections, and also form a basis for further research.

Methodology: This was a retrospective review of laboratory records of all ear swabs submitted for culture over a two year period in the Korle Bu Teaching Hospital Accra, Ghana. Data was obtained on demographic characteristics of patients, clinical diagnosis, isolated organisms and antibiotic susceptibility patterns of the isolated organisms. Data was analyzed by simple descriptive statistics.

Results: A total of 351 ear swabs were received by the laboratory for processing over the two year period. Of these $277(78.9 \%)$ had microorganisms isolated. A significant number127 (47\%) was obtained from children under five years. Pseudomonas spp was the commonly isolated organism 121(46\%) followed by Staphylococcus aureus 33(12.5\%) and Proteus spp $32(12.2 \%)$. Candida was the commonest isolated fungi $9(69.2 \%)$. Susceptibility of Pseudomonas spp to commonly used ototopics (ciprofloxacin \& gentamicin) was $93 \%$ and $74 \%$ respectively.

Conclusions: Most cases of the discharging ear were found in children under the age of five years. The most common bacteriologic cause of the discharging ear was Pseudomonas spp followed by Staphylococcus aureus. Candida species was the commonest fungal cause of ear discharge. Ciprofloxacin and gentamicin are effective ototopic antimicrobial agents for empirical treatment of the discharging ear.

Key words: Ear discharge, antimicrobial agents, susceptibility, ototopics, Korle-Bu teaching hospital

\section{INTRODUCTIONS}

Ear discharge is a common presentation in medical practice. It affects people of all age groups but primarily it is a condition of children. ${ }^{1-3}$ inflammatory conditions of the external and middle ear account for most ear discharges. These include acute and chronic otitis externa, acute otitis media, chronic suppurative otitis media with or without cholesteatoma, and malignant otitis externa. ${ }^{2,4-6}$ It may also occur as a result of tympanostomy and ventilation tube insertion. ${ }^{2}$

The incidence rate of acute otitis media worldwide is $10.85 \%$ with $51 \%$ occurring in under-fives. That of chronic suppurative otitis media is $4.76 \%$ with $22.6 \%$ occurring annually in under-fives. It is estimated that twenty thousand people die each year from otitis media; and the overall burden of these diseases is borne in the poorest countries. ${ }^{1}$

The bacteriologic spectrum of ear discharge is variable. Majority of practitioners treat discharging ears empirically with systemic and topical antibiotics, and do not routinely send specimens of the discharge for microbiological analysis unless the discharge is refractory to treatment, ${ }^{6}$ however, several authors suggest otherwise. ${ }^{4,7}$ Like any other disease of microbiologic origin, it is important to know the spectrum of organisms causing ear discharge and their antibiograms.

In Ghana the only existing data dates back to 27 years ago $(1987)^{8}$ The current study was carried out to determine the current aetiological agents of ear discharge and their antibiograms; data that would guide empirical treatment of ear infections and also form a basis for further research to improve quality of care extended to patients. 


\section{METHODS}

This was a retrospective review of laboratory records of all ear swabs taken from patients with ear discharge from $1^{\text {st }}$ May 2011 to $30^{\text {th }}$ April 2013 in the Korle-Bu Teaching Hospital, Ghana

\section{Study area:}

The Korle-Bu Teaching Hospital (KBTH), the largest tertiary health care facility in Ghana, was the survey site. The bacteriology unit (The Central La Laboratory) was used as the survey centre. Samples from patients to the Central Laboratory were from the main Clinical Departments i.e. Internal Medicine, Surgery, Child Health and Obstetrics and Gynaecology (OBGYN) as well as all allied health units of the Teaching Hospital. The KBTH has a bed capacity of 2000 and over 3000 staff.

The Central Outpatients Departments of the Hospital run general and specialised medical and surgical clinics from Monday to Friday. Patients requiring admission or specialist services offered in other areas of the hospital are referred to the appropriate ward or clinic from the outpatients units. In 2010, a total of 357,086 patients were seen at the central outpatient department, averagely, 29,757 patients were seen per month; according to the Annual Report of KBTH, 2010.

\section{Specimen collection and processing:}

The entire specimen were taken using dry sterile cotton swabs and processed at the bacteriology unit of the Korle-Bu Teaching Hospital (Central Laboratory). All swabs were cultured on blood, chocolate and MacConkey agar and incubated aerobically at $37^{\circ} \mathrm{C}$ for 24 hours. Isolated organisms were identified using standardized biochemical tests, including urease and indole production, citrate utilization, hydrogen sulphide gas production and fermentation of sugars. The biochemical media used included Simon's Citrate medium, Urea and Triple Sugar Iron agar (TSI). ${ }^{9}$ Antimicrobial susceptibility testing was performed according to Clinical and Laboratory Standards Institute (CLSI) guidelines. ${ }^{10}$ Acinetobacter species and $S$. epidermidis were deemed as skin flora and probable contaminants as such no susceptibility testing was performed on them.

\section{Data collection}

A retrospective review of laboratory records of all ear swabs taken from patients with ear discharge over a two-year period from all departments and units of the Hospital were reviewed. Data was retrieved from laboratory record books with a data abstraction form. Data abstracted from the record books included basic demographic characteristics of patients (age and sex), clinical diagnosis, isolated organisms and antibiotic susceptibility patterns of the isolated organisms. . In all a total of 351 ear swabs were received by the laboratory for processing over the two year period.

\section{Data analysis}

Data obtained on demographic characteristics of patients, clinical diagnosis, isolated organisms and antibiotic susceptibility patterns of the isolated organisms were analyzed by simple descriptive statistics (i.e. proportions, ratios and percentages). Age of the patients were categorized into $\leq 1,2-4,5-13,14-19,20-44,45-$ 64 and $\geq 65$ years, to determine common organisms in the ear discharges of infants, children under 5 years, school age children and paediatric patients, young adults, older adults and the elderly.

The agents isolated were categorized into Enterobacteria, Gram positive organisms, Pseudomonas species, Fungi, and Acinetobacter species. The microbial agents were tested for antibiotic susceptibility using the following common antibiotics- Ampicillin, Augmentin, gentamicin, amikacin, ciprofloxacin, levofloxacin, cefuroxime, cefotaxime, chloramphenicol, cotrimoxazole, tetracycline and meropenem.

Data from abstraction form were entered into Microsoft Excel 2007 and imported into Statistical Package for Social Sciences IBM (SPSS VERSION 21) for analysis.

\section{RESULTS}

A total of 351 ear swabs were received by the laboratory for processing over the two year period. Of these $277(78.9 \%)$ had microorganisms being isolated from the discharge.

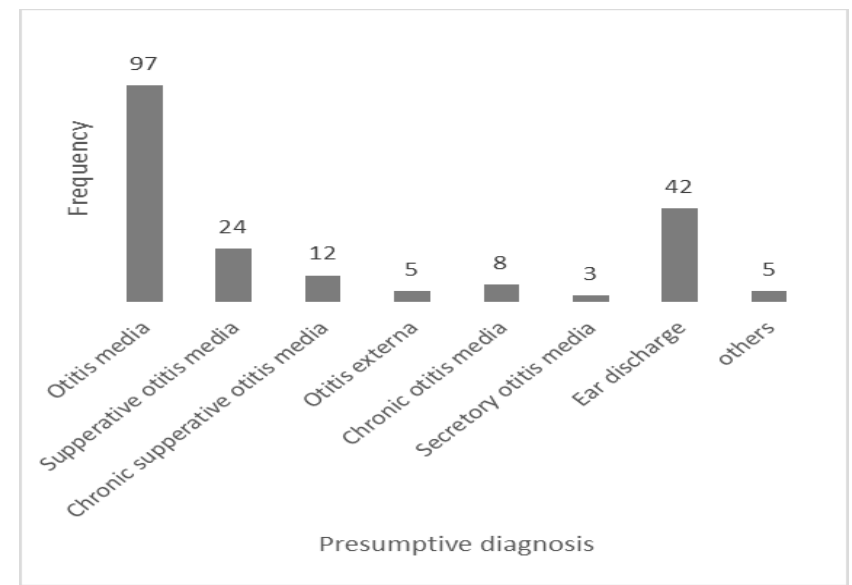

Figure 1 Frequency of presumptive clinical diagnosis on ear discharge from patients in the Korle-Bu Teaching Hospital 
Table 1 Age and sex characteristics of patients

\begin{tabular}{|c|c|c|c|c|c|c|c|c|}
\hline \multirow{2}{*}{ Sex } & \multicolumn{7}{|c|}{ Age Groups } & \multirow{2}{*}{ Total (\%) } \\
\hline & $\leq 1(\%)$ & $2-4(\%)$ & $5-13(\%)$ & $14-19(\%)$ & $20-44(\%)$ & $45-64(\%)$ & $\geq 65(\%)$ & \\
\hline Male & $\begin{array}{l}39 \\
(60.9)\end{array}$ & $\begin{array}{l}41 \\
(65.1)\end{array}$ & $\begin{array}{l}39 \\
(70.9)\end{array}$ & $\begin{array}{l}7 \\
(63.6)\end{array}$ & $\begin{array}{l}25 \\
(47.2)\end{array}$ & $\begin{array}{l}14 \\
(73.7)\end{array}$ & $\begin{array}{l}6 \\
(85.7)\end{array}$ & $\begin{array}{l}171 \\
(62.9)\end{array}$ \\
\hline Female & $\begin{array}{l}25 \\
(39.1)\end{array}$ & $\begin{array}{l}22 \\
(34.9)\end{array}$ & $\begin{array}{l}16 \\
(29.1)\end{array}$ & $\begin{array}{l}4 \\
(36.4)\end{array}$ & $\begin{array}{l}28 \\
(52.8)\end{array}$ & $\begin{array}{l}5 \\
(26.3)\end{array}$ & $1(14.3)$ & $101(37.1)$ \\
\hline Total & $64(100)$ & $63(100)$ & $55(100)$ & $11(100)$ & $53(100)$ & 19(100) & $7(100)$ & $272(100)$ \\
\hline
\end{tabular}

A single organism was isolated from 232(83.8\%) samples whilst $45(16.2 \%)$ samples had two organisms isolated; fifty-nine isolates were deemed contaminants.

Table 1 shows the age and sex distribution of the study patients, whilst Figure 1 shows the presumptive diagnosis written on request forms. Fifty $(51.5 \%)$ of the patients with otitis media were under five years.

Table 2 Summary of isolated organisms from ear discharge of patients

\begin{tabular}{|c|c|c|}
\hline Isolated organism & $\begin{array}{l}\text { Frequency } \\
\text { (Grand total=322) }\end{array}$ & Percentage \\
\hline Gram Negative organisms & 220 & 68.3 \\
\hline Gram positive organisms & 89 & 27.6 \\
\hline Fungi & 13 & 4.0 \\
\hline Total & 322 & 100 \\
\hline \multicolumn{3}{|l|}{ Enterobacteria } \\
\hline Proteus spp & 32 & 35.6 \\
\hline Escherichia coli & 13 & 14.4 \\
\hline Providencia spp & 6 & 6.7 \\
\hline Klebsiella spp & 5 & 5.6 \\
\hline Citrobacter spp & 22 & 24.4 \\
\hline Serratia spp & 2 & 2.2 \\
\hline Enterobacter spp & 9 & 10 \\
\hline Morganella spp & 1 & 1.1 \\
\hline Total & 90 & 100 \\
\hline \multicolumn{3}{|l|}{ Gram positive organisms } \\
\hline $\begin{array}{l}\text { Streptococcus spp } \\
\text { Streptococcus pneumoniae }\end{array}$ & $\begin{array}{l}2 \\
3\end{array}$ & $\begin{array}{l}2.2 \\
3.4\end{array}$ \\
\hline Enterococcus spp & 1 & 1.1 \\
\hline Staphylococcus epidermidis & 50 & 56.2 \\
\hline Staphylococcus aureus & 33 & 37.1 \\
\hline Total & 89 & 100 \\
\hline \multicolumn{3}{|l|}{ Fungi } \\
\hline $\begin{array}{l}\text { Candida spp } \\
\text { Aspergillus spp }\end{array}$ & $\begin{array}{l}9 \\
4\end{array}$ & $\begin{array}{l}69.2 \\
30.8\end{array}$ \\
\hline Total & 13 & 100 \\
\hline \multicolumn{3}{|l|}{ Non-Fermentative bacteria } \\
\hline Acinetobacter spp & 9 & 6.9 \\
\hline Pseudomonas spp & 58 & 44.6 \\
\hline Pseudomonas aeruginosa & 63 & 48.5 \\
\hline Total & 130 & 100 \\
\hline
\end{tabular}

Table 2 shows the susceptibility patterns of bacterial isolates from ear discharge of patients and indicates that the most commonly isolated organism was Pseudomonas spp.

Table 3 demonstrates the distribution of isolated organisms per different age groups of patients. Most of the organisms were isolated from the age group 0-5 years (e.g. the distribution of enterobacteria among the age groups $0-5$ was $39(43.4 \%)$ compared to $2(3.3 \%)$ among adults aged $\geq 65$ years.

Table 3 Summary of age groups of patients and isolated organisms from ear discharge

\begin{tabular}{|l|l|l|l|l|l|l|}
\hline $\begin{array}{l}\text { Age } \\
\text { catego- } \\
\text { ry }\end{array}$ & $\begin{array}{l}\text { Entero- } \\
\text { bacteria } \\
\mathbf{( \% )}\end{array}$ & $\begin{array}{l}\text { Gram } \\
\text { positive } \\
\text { organisms } \\
(\%)\end{array}$ & $\begin{array}{l}\text { Pseudo- } \\
\text { monas } \\
\text { spp (\%) }\end{array}$ & $\begin{array}{l}\text { Fungi } \\
\mathbf{( \% )}\end{array}$ & $\begin{array}{l}\text { Aci- } \\
\text { netobac- } \\
\text { ter spp } \\
\text { (\%) }\end{array}$ & $\begin{array}{l}\text { Total } \\
\text { (\%) }\end{array}$ \\
\hline$\leq 1$ & $15(16.7)$ & $22(24.7)$ & $31(25.6)$ & $2(15.4)$ & $3(37.5)$ & $73(22.7)$ \\
\hline $2-4$ & $24(26.7)$ & $21(23.6)$ & $26(21.5)$ & $2(15.4)$ & $3(37.5)$ & $76(23.6)$ \\
\hline $5-13$ & $18(19.8)$ & $15(16.9)$ & $30(24.8)$ & $3(23.1)$ & $0(0)$ & $66(20.5)$ \\
\hline $14-19$ & $6(6.7)$ & $4(4.5)$ & $4(3.3)$ & $0(0)$ & $0(0)$ & $14(4.3)$ \\
\hline $20-44$ & $21(23.3)$ & $19(21.3)$ & $14(11.6)$ & $4(30.8)$ & $1(11.1)$ & $59(18.3)$ \\
\hline $45-64$ & $4(4.4)$ & $7(7.9)$ & $10(8.3)$ & $1(7.7)$ & $2(22.2)$ & $24(7.5)$ \\
\hline$\geq 65$ & $2(2.2)$ & $1(1.1)$ & $6(4.2)$ & $1(7.7)$ & $0(0)$ & $10(3.1)$ \\
\hline Total & $90(100)$ & $89(100)$ & $121(100)$ & $13(100$ & $9(100)$ & $322(100)$ \\
\hline
\end{tabular}

Table 4 indicates the susceptibility patterns of the various isolates. Enterobacteria was most susceptible to amikacin $(77 / 85 ; 90.6 \%)$ followed by cefotaxime (63/81; 77.8\%). Pseudomonas spp was most susceptible to ceftazidime $(99 / 103 ; 96.1 \%)$ and then ciprofloxacin $(80 / 86 ; 93 \%)$. Regarding Gram positive organisms, Staphylococcus aureus was most susceptible to cloxacillin $(30 / 31 ; 96.8 \%)$. 
Table 4 Antimicrobial susceptibility patterns of microbial isolates from ear discharge

\begin{tabular}{|c|c|c|c|}
\hline $\begin{array}{l}\text { Antimicrobial } \\
\text { agent }\end{array}$ & $\begin{array}{l}\text { Resistant } \\
(\%)\end{array}$ & $\begin{array}{l}\begin{array}{l}\text { Susceptible } \\
(\%)\end{array} \\
\end{array}$ & $\begin{array}{l}{ }^{*} \text { Total } \\
(\%)\end{array}$ \\
\hline \multicolumn{4}{|l|}{ Enterobacteria } \\
\hline Ampicillin & $55(94.8)$ & $3(5.2)$ & $58(100)$ \\
\hline Augmentin & $18(58.1)$ & $13(41.9)$ & $31(100)$ \\
\hline Gentamicin & $25(31.2)$ & $55(68.8)$ & $80(100)$ \\
\hline Amikacin & $8(9.4)$ & $77(90.6)$ & $85(100)$ \\
\hline Ciprofloxacin & $12(27.9)$ & $31(72.9)$ & $43(100)$ \\
\hline Levofloxacin & $4(20)$ & $16(80)$ & $20(100)$ \\
\hline Cefuroxime & $27(34.2)$ & $52(65.8)$ & $79(100)$ \\
\hline Cefotaxime & $18(22.2)$ & $63(77.8)$ & $81(100)$ \\
\hline Chloramphenicol & $48(81.4)$ & $11(18.6)$ & $59(100)$ \\
\hline Co-trimoxazole & $38(66.7)$ & $19(33.3)$ & $57(100)$ \\
\hline Tetracycline & & $4(7)$ & $57(100)$ \\
\hline $\begin{array}{l}\text { Gram-positive } \\
\text { organisms. }\end{array}$ & $53(93)$ & & \\
\hline Ampicillin & $23(95.8)$ & $1(4.2)$ & $24(100)$ \\
\hline Augmentin & $6(33.3)$ & $12(66.7)$ & $18(100)$ \\
\hline Gentamicin & $10(33.3)$ & $20(66.7)$ & $30(100)$ \\
\hline Penicillin & $34(97.1)$ & $1(2.9)$ & $35(100)$ \\
\hline Cefuroxime & $10(30.3)$ & $23(69.7)$ & $33(100)$ \\
\hline Cloxacillin & $1(3.2)$ & $30(96.8)$ & $31(100)$ \\
\hline Cotrimoxazole & $17(81)$ & $4(19)$ & $21(100)$ \\
\hline Tetracycline & $13(62)$ & $8(38)$ & $21(100)$ \\
\hline Erythromycin & 11(46) & $13(54)$ & $24(100)$ \\
\hline \multicolumn{4}{|l|}{$\begin{array}{l}\text { Pseudomonas spe- } \\
\text { cies }\end{array}$} \\
\hline Gentamicin & $28(26)$ & $80(74)$ & $108(100)$ \\
\hline Amikacin & $12(12.5)$ & $84(87.5)$ & $96(100)$ \\
\hline Ciprofloxacin & $6(7)$ & $80(93)$ & $86(100)$ \\
\hline Levofloxacin & $7(13.2)$ & $46(86.8)$ & $53(100)$ \\
\hline Ceftazidime & $4(3.9)$ & $99(96.1)$ & $103(100)$ \\
\hline
\end{tabular}

*The varying denominators for the antimicrobial agents are due to periodic shortages of reagents in the laboratory which affected the testing panel during the period of review.

\section{DISCUSSION}

Pseudomonas species was the most commonly isolated organism in our study. It is a common environmental organism usually found in warm and moist environment, and is known to colonize the external auditory canal. ${ }^{2}$ It is commonly associated with otitis externa and chronic superlative otitis media. ${ }^{2,6,11}$

In an earlier study in Ghana ${ }^{8}$ Pseudomonas aeruginosa ranked second to Streptococcus pyogenes as a cause of otitis media. In similar studies conducted in Nigeria, Greece and, Ethiopia Pseudomonas aeruginosa was the most commonly isolated organism; $34.6 \%$ in Nigeria $^{7}$ and $26 \%$ in Greece ${ }^{11}$, whilst it ranked third, $13.4 \%$ in Ethiopia. $^{12}$ In chronic suppurative otitis media it has been found to be the commonest isolated organism. This has been corroborated in studies in Nigeria ${ }^{13}$, Sri lanka ${ }^{14}$, India ${ }^{15}$ and Pakistan. ${ }^{16}$

Common causes of otitis media i.e. Haemophilus influenzae, Streptococcus pneumoniae and Moraxella catarrhalis $^{2,3,6,7}$ were rarely isolated despite otitis media being the highest recorded presumptive diagnosis in our study. These findings are similar to that of an earlier study conducted in Ghana. ${ }^{8}$ This may be indicative of a limited role played by these organisms in ear infections in our environment. It may also be as a result of inability of non-Otolaryngology doctors to appropriately diagnose the causes of ear discharge. However the high rate of Pseudomonas species isolation may point to a possible under diagnosis of chronic supperative otitis media and otitis external in the hospital.

Candida species was identified as the common nonbacterial cause of ear discharge, this is at variance with findings in India and Greece where Aspergillus species was the commonest isolated fungus. ${ }^{11,15}$ A significant number of patients 127 (47\%) in our study were in the under-five age category. This is in agreement with available literature which shows that the majority of ear infections occur in children less than five years of age. 1,3

The most common mode of treatment for a discharging ear is aural toileting and use of ototopic agents. ${ }^{2,4,6}$ Susceptibility of Pseudomonas species to ciprofloxacin and gentamicin; commonly used ototopic agents were high $93 \%$ and $73 \%$ respectively. Susceptibility of enterobacteria to these two antibiotics was also relatively high in our study. This means ciprofloxacin can be used as an empirical ototopic agent in the management of ear discharge in our setting. Several studies recommend ciprofloxacin as a safe and effective ototopic agent for the management of discharging ears in both adults and children.

This is because of its broad spectrum of activity, including coverage of Pseudomonas spp, Staphylococcus and Streptococcus spp ${ }^{2,4,6,15}$ Gentamicin may also be used as empirical treatment for ear infections with a discharge in this environment based on the susceptibility patterns identified from this review. However, it has to be used with care and for limited periods because of its potential ototoxicity. 6,17 


\section{CONCLUSIONS}

The discharging ear is a common presentation in this large hospital, typically found in children under the age of five years. The most common bacteriologic cause of the discharging ear is Pseudomonas species followed by Staphylococcus aureus. Candida species is the commonest fungal cause of ear discharge. Ciprofloxacin and gentamicin are effective ototopic antimicrobial agents for empirical treatment of the discharging ear.

\section{Limitations}

Demographic and clinical data was not completely analyzed on account of inadequate information on request cards. Vital information on the clinical units where the ear discharge was sent from could not be determined; due to inadequate data from the laboratory records. Anaerobes were not isolated because our laboratory doesn't perform anaerobic cultures routinely. Due to periodic shortages in reagents the testing panel was reduced for particular periods during the period under review, thus affecting the denominators for the various antibiotics. However, the analysis gives enough basis for the application of the recommendations for health delivery in the Teaching Hospital

\section{RECOMMENDATIONS}

There is the need to conduct studies into individual infective causes of ear infections, their microbial profile and anti-microbial susceptibility patterns to further guide therapy. Continuous medical education programmes and seminars should be held periodically to help practitioners improve their ability to diagnose ear infections. Clinicians must be encouraged to complete laboratory request forms appropriately to improve quality of laboratory results and also aid research.

\section{ACKNOWLEDGEMENTS}

We are grateful to all the patients from whom the records were obtained and to the staff of the Microbiology Department of the Korle-Bu Teaching Hospital for their support.

\section{REFERENCES}

1. Monasta L, Ronfani L, Marchetti F, Montico M, Vecchi B L, Bavcar A, et al. Burden of Disease Caused by Otitis Media: Systematic Review and Global Estimates. PLoS ONE. 2012; 30;7(4):e36226.

2. Ramsey AM. Diagnosis and Treatment of the Child With a Draining Ear. $J$ Paediatr Healthc.2002; 16:161-9.

3. Berman S. Otitis Media in Developing Countries. Paediatrics 1995; 96:126-31.
4. Seedat RY. The discharging ear: A practical approach. Contin Med Educ. 2008;11;22(5):246.

5. Ruiz M, Bernaldez P, Morales G, Quantin L. Causes of Otorrhea in Children: Clinical Findings in Ninety-Two Cases. Otolaryngol Head Neck Surg.2005; 133(2):P246-P246.

6. Amin M, Blayney A. The discharging ear. $J E N T$ Mastercl. 2010;3(1):68-72.

7. Oni AA, Nwaorgu OGB, Bakare RA, Ogunkunle MO, Toki RA. The Discharging Ears In Adults In Ibadan, Nigeria Causative Agents And Antimicrobial Sensitivity Pattern. Afr J Clin Exp Microbiol.2002;3(1):3-5.

8. Brobby GW, Zadik P. Bacteriology of otitis media in Ghana. Tropical Doctor.1987;17(2):91-92

9. Vandepitte $\mathrm{J}$ et al. Basic procedures in Clinical Bacteriology.2003;WHO; pg 86-97, 2nd edition,

10. Cockerill FR, et al, Performance standards for antimicrobial susceptibility testing; Twenty-second informational supplement.M100-S-17, Vol.27 No.1, Jan 2007

11. Bardanis J, Batzakakis D, Mamatas S. Types and causes of otorrhea. Auris Nasus Larynx. 2003;30(3):253-7.

12. Getachew Tesfaye, Asrat D, Yimtubezinash Woldeamanuel, Messele Gizaw. Microbiology of discharging ears in Ethiopia. Asian Pac J Trop Med. 2009;2(1):60-7.

13. Afolabi O, Salaudeen A, Ologe F, Nwabuisi C, Nwalolo C Pattern of bacterial isolates in the middle ear discharge of patients with chronic suppurative otitis media in a tertiary hospital in North central Nigeria. Afr Health Sci. 2012;12(3):362-8.

14. Dayasena R, Dayasiri M, Jayasuriya C, Perera D. Aetiological agents in chronic suppurative otitis media in Sri Lanka. Australas Med J. 2011;4(2):101-4.

15. Vishwanath S, Mukhopadhyay C, Prakash R, Pillai S, Pujary K, Puiary P. Chronic Suppurative Otitis Media: Optimizing Initial Antibiotic Therapy in a Tertiary Care Setup. Indian J Otolaryngol Head Neck Surg.2012;64(3):285-9.

16. Sattar A, Alamgir A, Sarfraz S, Nasir J, Badar-eAlam. Bacterial spectrum and their sensitivity pattern in patients of chronic suppurative otitis media. J Coll Physicians Surg Pak. 2012;22(2):128-9.

17. Phillips JS, Yung MW, Burton MJ, Swan IRC. Evidence review and ENT-UK consensus report for the use of aminoglycoside-containing ear drops in the presence of an open middle ear. Clin Otolaryngol Off J ENT-UK Off J Neth Soc OtoRhino-Laryngol Cervico-Facial Surg. 2007; 32(5):330-6 